\title{
The Foundation for a Smoke-Free World after two years: can it be trusted?
}

\author{
Jean-Francois Etter ${ }^{1}$
}

1 University of Geneva

\section{Abstract}

\section{Background}

The Foundation for a Smoke-Free World (FSFW) was launched in 2017 and is funded by Philip Morris International (PMI). We conducted interviews and reviewed documents to evaluate the FSFW and assess whether it can be trusted to produce useful and unbiased research.

\section{Analysis}

The FSFW approved grants for USD 156 million since its inception. Several grantees come from low- and middleincome countries, where resources for tobacco control are scarce. The FSFW implements a specific approach that relies on reduced-risk products, agricultural transformation, and transformation of the tobacco industry. Existing tobacco control approaches have had limited impact in some countries, they achieved change too slowly and an acceleration is needed. We shall see whether the Foundation's original approach can provide this acceleration, but it is too soon the judge its output. The FSFW's potential is undermined by opposition from the World Health Organization and other tobacco control organizations, and by a difficulty in attracting experienced researchers. It is quite possible that new ideas can come from people outside the field, but inexperienced grantees may have difficulty producing useful work and understanding the importance of independence from the tobacco industry. The decision to obtain funding exclusively from PMI is at the center of the criticism against the Foundation, it undermines trust and creates risks for board members, grantees and staff, some of whom have been harassed by tobacco control people. More transparency on the FSFW's governance, functioning, grants and grantees is advisable, but obtaining more transparency will require a tougher condemnation of harassment.

\section{Conclusions}

Scrutiny is continuously needed on the Foundation's independence, governance and output, as for any other scientific or tobacco control effort. The Foundation will ultimately be evaluated on its impact on smokers and poor tobacco farmers and on its ability to support its partners if they are harassed.

\section{Introduction}

The Foundation for a Smoke-Free World (FSFW) was launched in September 2017, it is funded by Philip Morris International (PMI), who committed to give it USD 1 billion over 12 years (USD 80 million per year). When it was launched, 
the Foundation was met with skepticism and hostility, in particular because it is funded by $\mathrm{PMI}^{\left[{ }^{11}\right.}$. Commentators feared that the Foundation lacked independence and was part of an alleged PMI's strategy to sow doubt and generate controversies ${ }^{[1][2][3]}$. The aim of this report is to examine the FSFW two years after it was launched and to assess whether it can be trusted to produce useful, unbiased research.

\section{Analysis}

\section{Elements examined}

We examined the Foundation's goals (declared and suspected), whether it is independent from PMI, whether it is sufficiently transparent, who are its directors, how the Foundation operates, who are the grantees, what projects are supported and what output was produced. We also examined how the Foundation was received by the public health and tobacco control communities, since this will determine how and whether the FSFW's scientific production will be used by other actors.

\section{Methods}

We reviewed the scientific literature, examined the Foundation's website and 2018 tax returns, conducted telephone interviews with two grantees, two FSFW board members, one former collaborator, one tobacco control expert with no conflicts of interest, and with the FSFW president, Derek Yach, whom we also met in person. We also conducted e-mail interviews with five tobacco control experts with no conflicts of interest (from USA, UK, and Canada), asking the same list of questions of all of them, and with one grantee and one FSFW board member. This was done in October and November 2019. The results were presented at a conference ${ }^{[4]}$, and we obtained feedback on this presentation from conference attendees and from the FSFW's president.

\section{The Foundations Goals}

According to its Certificate of Incorporation, the FSFW "shall be operated exclusively for charitable, scientific and educational purposes", and its objectives are, inter alia, "to support independent scientific research free from the influence of any commercial entity ", "to support research and projects regarding alternatives to cigarettes and other combustible tobacco products", "to scrutinize (...) the tobacco industry ", and to "research the effect of reduced demand for leaf tobacco on farmers"[5]. The Foundation allows PMI a charitable tax deduction (and is therefore indirectly supported by the taxpayers who have to carry the corresponding shortfall of tax income), and it is registered in Delaware, probably for fiscal reasons.

The overwhelming majority of the harm caused by tobacco is caused by cigarettes and other combustible products, and replacing them with non-combustible products will most certainly decrease harm at population level ${ }^{[6][7]}$. The Foundation aims at reducing the damages caused by combustible tobacco products, not at reducing consumption of non-combustible 
tobacco or nicotine products ${ }^{[5]}$. PMI's current industrial strategy is to replace cigarettes with various non-combustible products $^{[8]}$. Even though the Foundation's goals differ from those of PMI, replacing combustible with non-combustible tobacco products is part of both PMl's and FSFW's strategies.

Is the Foundation's real goal to create doubt, divisions and undermine tobacco control?

PMI has a historical record of scientific misconduct9][10]. PMI led several scientific initiatives to undermine tobacco control, including the Whitecoat Project and the INBIFO laboratory (both were efforts to create artificial controversy about the effects of environmental tobacco smoke ${ }^{[9][10]}$. Some fear that the FSFW is just another initiative in the same direction? ${ }^{[2]}$ but any judgment on the FSFW's alleged hidden goals is ultimately a matter of opinion.

Willingly or not, the FSFW created controversies and divisions among the tobacco control community. However, the harassment by academics and by tobacco control people that some FSFW grantees and board members report also creates divisions, and bias can be observed on both 'sides' of the tobacco harm reduction debate. Scrutiny of the Foundation is continuously needed, as should be the case with all scientific activities and output.

Is the Foundation independent from Philip Morris International?

During the initial steps of the Foundation's creation, Yach negotiated the Foundation's purpose, objectives and funding with PMI. He was paid by PMI during these talks, which were conducted privately and without external oversight. The Foundation's president was selected by PMI and he led the process of selecting the board of directors (none of whom had prior connections to PMI) and the Foundation's team. PMI not only provided the initial funding but is the Foundation's sole source of funding. All this does not speak in favor of the Foundation's independence.

The authors of an analysis of FSFW's certificate of incorporation, bylaws and pledge agreement with PMI found loopholes in these documents (e.g. protection against conflicts of interest) ${ }^{[11]}$. Other authors presented in 2009 a list of criteria for the acceptability of tobacco industry-funded research, e.g. transparency and protection against conflicts of interest ${ }^{[12]}$. The FSFW says it aims at meeting these criteria ${ }^{[13]}$, but the authors disagree, in particular because the FSFW's bylaws say nothing about which relationships with the tobacco industry are not acceptable, and because the Foundation may allow PMI to realize public relations gains ${ }^{[14]}$. The authors of both articles conclude that the FSFW cannot be regarded as independent.

In interviews, the president and board members said that they did all they possibly could to be independent from PMI and that they welcome suggestions about what more they can do. They said that there is no interference from PMI with the direction and management of the Foundation, nor with the grant-making process, and that the FSFW operates independently from PMI.

Whatever the FSFW does, the perception of insufficient independence may never go away, but there is a trade-off between the need for independence and the need for oversight and accountability. Who better than its sole source of income can hold the Foundation accountable? 
Is the Foundation sufficiently transparent?

US laws require transparency about how every foundation's money is spent, and the FSFW's tax returns, which include the names of grantee organizations and the amount per grant, are published on the FSFW website. In interviews, board members and the president told me that all research will be published, but much of the information that would be needed to form an informed opinion about the Foundation is not available on its website. This includes details on grants, the names of the grantees, details on the grant attribution process, on the decision making, on the Foundation's output and scientific production, and on its monitoring and evaluation procedures. The Foundation published the minutes of its board meetings until May 2019, but does not publish them anymore (some of the previously published minutes are still available on the Archive.org website). The Foundation is not legally required to disclose those minutes, and given the climate of hostility against the FSFW, publishing those minutes is reportedly perceived by its president as counterproductive.

The names of members of the scientific advisory council were kept hidden for some time before they were finally disclosed in December 2019. Temporarily hiding these names was reportedly done to protect board members from harassment, but was seen as unacceptable by the experts we talked to.

The FSFW may not be less transparent than many other foundations and grant-making agencies, and it is not legally required to disclose more information than it currently does. However, these arguments should not be used to withhold information that is necessary for outsiders to form an opinion on the Foundation's independence, work and output. Because of its funding source, the FSFW is subjected to more media coverage and is under more intense scrutiny than other foundations or grant-making agencies, and a higher level of transparency is advisable and would help build trust.

Who are the Foundation's directors?

In addition to Yach, only one member of the board of directors has expertise on tobacco, and his expertise is in agriculture, not in tobacco control. The other directors' backgrounds are in accounting, law, private business, science, new technologies, and other competencies that are relevant and necessary to manage a large foundation. The fact that except the president, none of the members of the board of directors has expertise on tobacco control, and that apparently none of them has prior expertise in the management of a large foundation, is a weakness. Nevertheless, two staff members with the title of vice-president have expertise on tobacco control, including a former collaborator of the U.S. Food and Drug Administration's Center for Tobacco Products and a former director of tobacco control at the International Union against Tuberculosis and Lung Disease. Several other staff members also have expertise in tobacco control, and there are renowned tobacco control experts on the scientific advisory council. In interviews with board members and with the Foundation's president, I was told that new members with tobacco control expertise will be added to the board of directors.

An examination of the board minutes revealed that four members of the board of directors already left. In interviews, I was told they left for various reasons, in particular because some of them were harassed by tobacco control and academic people. 
The Foundation's tax returns indicate that the president was compensated USD $795^{\prime} 000$ in 2018, and that members of the board of directors were either not paid or were paid up to USD $88^{\prime} 000$ for a part-time job (25\%). The median salary for the five highest paid employees in 2018 was USD $344^{\prime} 000^{[15]}$. Some of the experts we spoke to frowned upon the level of salary of the FSFW's president, which casts some shadow over his motivations.

How was the money spent in 2019?

Information we obtained from the Foundation indicated that in the fiscal year 2019, USD 32 million were spent on grants, 4 million on communication, and 20 million on operating expenses. One may ask why spend so much money on communication and operation. Based on the high communication expenses (USD 7 million in 2018), the authors of an article in The Lancet concluded that the FSFW is primarily a public relations operation ${ }^{[16]}$. In interviews and in a published response to this article ${ }^{[17]}$, Yach pointed that costs for public relations are justified during the initial stage of setting up a large foundation, and that the communication costs are also related to the level of hostility the Foundation was subjected to.

In interviews with board members and with the president, we were told that the success rate for grant applications was about one third, that USD 156 million had been approved for grants, and that 90 grants had been approved for 150 researchers worldwide. Of the USD 156 million approved for grants, 109 million went for health, science \& technology, 29 million for agriculture transformation, 13 million for tobacco industry transformation, and 5 million for education and advocacy. Therefore, it appears that the FSFW is functioning, vetting and approving grants. The success rate of grant applications to the FSFW (one third) is higher than the success rate of grant applications to the U.S. National Institutes of Health $(20 \%)^{[18]}$, but comparable to the success rate at Cancer Research U.K! ${ }^{[9]}$, and lower than the success rate at the Swiss National Science Foundation (47\% ${ }^{[20]}$.

Who are the grantees?

The names of grantee organizations, but not those of individual grantees, are listed on the Foundation's tax returns and on its website. Many of these organizations were not previously involved in tobacco control. Even though the grantees names are not disclosed (reportedly to protect them from harassment), it is evident that the FSFW has difficulty attracting experienced tobacco control researchers.

The countries that received the largest grant money from the Foundation are the USA (USD 56 million, largely for agricultural transformation in Malawi), Italy (USD 30 million, mostly for a center in Sicily, in particular for a project to train scientists from low- and middle-income counties), Malawi (29 million, for agricultural transformation), New Zealand (9.6 million, mostly for a center for smoking cessation in indigenous people), the UK (9.5 million), Germany (2.9 million), and also the United Arab Emirates, Switzerland, Pakistan, Bangladesh, South Africa, Liberia, Maldives, and Greece. Thus, several grantee organizations come from low- and middle-income countries, where resources for tobacco control are scarce.

In interviews, the grant vetting process was described by board members as operational, robust, with multiple decision 
layers, and with a thorough scrutiny of applications and applicants. However, the grant section of the FSFW website is not sufficiently informative: the projects are described in a few words only, and the names of the grantees and their list of publications are not disclosed. In interviews, grantees and board members told me that many innovative projects are in the pipeline, but because of the scarcity of information on these projects on the Foundation's website, it is hard to know what these projects are exactly, why they were selected, and to form an opinion on their quality, innovation potential, and on the competence of grantees. Disclosing more information on the grant vetting process, on grants and grantees would help build trust.

In interviews, two grantees told me that there was no interference from the FSFW in their work, and no attempt to influence their output.

The Foundation's output and production

It was difficult to track the Foundation's output. However, several reports are available on the Foundation's website and on the centers' websites (e.g. the New Zealand center) ${ }^{[21]}$. These reports cover tobacco harm reduction, smoking cessation products and services, the global nicotine and tobacco markets, industry transformation, insurer perspectives on smoking risks, and a global poll of smokers. These reports are not peer-reviewed scientific publications and are intended to guide the activities of the Foundation and of other tobacco control organizations at a global level. On the whole, it is too soon to judge the FSFW's output.

There are few other funding sources for tobacco harm reduction at this level, in particular in low- and middle-income countries. Because of the level of the FSFW's funding and the predictable volume of its future output, it will be difficult to ignore its scientific production. The Foundation's approach is original, in particular its focus on reduced-risk products and on agriculture transformation (mainly in Malawi), and its engagement with the tobacco industry (aimed at persuading it to replace cigarettes with non-combustible tobacco products). Some of the tobacco control experts we consulted expressed doubts in particular about the chances of success of the Foundation's strategy to transform the tobacco industry, but we shall wait to see whether the FSFW's efforts in this specific area have an impact.

How was the FSFW received?

A review of the media coverage of the FSFW concluded that this coverage was overwhelmingly negative ${ }^{[1]}$. The media presented the FSFW as not credible because of its funding by PMI, and the media reporting was framed by doubt and disapproval. A frequent opinion was that the FSFW creation was disingenuous, as PMI simultaneously continued to undermine tobacco control laws in many countries ${ }^{[1]}$. The reactions of medical journals and of the public health and tobacco control communities were also mostly negative ${ }^{[2][3][11][16]}$. Thus, if creating the FSFW was primarily a public relations operation for PMI, one may ask whether it has been so successful to date.

A major challenge met by the Foundation is the opposition from the World Health Organization (WHO) and other organizations, in particular the Bloomberg Foundation. The WHO advised member states not to collaborate with FSFW, and this boycott may limit the Foundation's impact. 
When asked why he did not obtain funding elsewhere, the Foundation's president responded that after trying but being unable to obtain the level of funding he needed, he concluded that the only way to obtain sufficient resources was to rely on the tobacco industry. This choice is at the center of the criticism against the Foundation, and it creates risks for all those associated with the FSFW: board members, grantees and staff.

Hostility against the Foundation's partners and grantees

An important problem is the reported harassment by academics and by tobacco control people of FSFW grantees, scientific advisory council members, board members, even of teenagers and their teachers who participated in an innovation competition for students ages 13-18 called the Conrad Challenge and supported by the Foundation. This must certainly alarm would-be grantees and would-be board members, and make it more difficult for the Foundation to enroll them.

One grantee said that «reactions were irritating rather than an onslaught», but other grantees reported that they were ostracized, silenced, excluded, even harassed and bullied, the worst situation being probably that of Dr Marewa Glover. Professor Glover received a large FSFW grant to reduce smoking in indigenous people in New Zealand ${ }^{[21]}$. Then, researchers at Otago University tried to stop local health authorities in New Zealand (called district health boards) working with her. The New Zealand Ministry of Health also warned district health boards it prefers they not work with her. She was the victim of cyber-bullying, misinformation and defamatory remarks, against which she took legal action. Her opponents contacted KiwiBank to try and stop her becoming a finalist in the New Zealander of the Year competition. She was among 3 finalists but did not win. Glover said: «They want to silence me», «What happened was like a public lynching», and «A cascade of 'damages' has ensued» [22].

The response of the scientific and tobacco control communities to this harassment has been weak to say the least, and there were very few denunciations of these unethical behaviors. Scientists and tobacco control people should stand more strongly against ad personam attacks and make it clear that they are not acceptable. Both 'sides' of the tobacco harm reduction debate are affected, as anti-e-cigarette people have been harassed too ${ }^{[23]}$. Boycotts and exclusion rarely produce positive results, and an already observable negative result is that this harassment pushes the FSFW to be less transparent about its functioning and the identity of grantees and partners.

After the Foundation's creation was announced in 2017, a shower of criticism ensued. Afterwards, it was probably predictable that the people associated with the FSFW would be targeted too. And this prediction soon materialized: some members of the board of directors resigned after they were harassed, grantees were harassed, the Foundation has difficulty attracting renowned scientists, and it keeps the names of individual grantees hidden to protect them from harassment. Even the names of members of the scientific advisory council were hidden for some time before they were finally disclosed. The Foundation will probably have to deal with this hostility during the entire course of its existence, and grantees may have to live with the consequences for the rest of their careers. Damage has been done and damage will be done to the Foundation's partners. Would-be partners are informed in advance of the risks involved in being associated with the Foundation, but information is not sufficient and the Foundation should probably do more to support its partners 
who are harassed.

\section{Discussion}

The FSFW appears to be operational, and innovative projects are reportedly under way, but can the Foundation be trusted to produce useful and unbiased research?

Some tobacco control experts (including the WHO) are opposed to the harm reduction approach and to the inclusion of new nicotine products in tobacco control policies, and they may never consider any of the FSFW's outputs useful. Some observers suspect that the FSFW is in fact a covert effort by PMI to undermine tobacco control, that the FSFW is irremediably biased and that the research produced with its money will never be trustworthy. On the other hand, some also see the FSFW as a sincere effort by its direction and team to produce useful and original research, and PMI is reportedly not intervening in the Foundation's operations and is possibly wary of being seen as too closely involved in the work of such a controversial venture. Willingly or not, the FSFW created controversies and divisions among tobacco control people, and also a fair amount of bad press for PMI.

Overall, it was difficult to obtain the information necessary to form an opinion on the FSFW's governance, functioning, grants and grantees. More transparency is advisable and would help build trust in the FSFW. However, obtaining more transparency will requires a tougher condemnation of harassment and of ad personam attacks.

The FSFW implements a specific approach that relies on new reduced-risk technologies, on agricultural transformation, and on engagement with the tobacco industry. This approach differs from the traditional approaches promoted by the WHO (through the FCTC) and other organizations, that emphasize taxation, bans on advertising, prevention of smoking initiation, warning labels, smoke-free laws, and treatment of addicted smokers ${ }^{[24]}$. Existing tobacco control approaches have had limited impact in some countries or in some subgroups, they achieved change too slowly and an acceleration is needed. We shall see whether the Foundation's original approach can provide this acceleration, and whether it is a useful complement to traditional tobacco control approaches, but the Foundation's potential is undermined by a boycott by WHO, by opposition from tobacco control people, by harassment, and by the difficulty in collaborating with renowned scientists.

The hostility with which the FSFW was met suggests that much of its future production will be rejected without a fair assessment. This may seriously reduce the usefulness of the FSFW's work. The fear of being harassed and the willingness to accept tobacco-related money has inevitably an impact on the people who apply for grants and who agree to collaborate with the Foundation. This self-selection of applicants may have an adverse impact on the usefulness and trustworthiness of the research the Foundation supports. The FSFW clearly has difficulty attracting experienced researchers, it is quite possible that new ideas and innovations can come from people outside the field, but inexperienced grantees may have difficulty producing useful work and understanding the importance of independence from the tobacco industry.

Scrutiny from independent observers is continuously needed on the Foundation's independence, transparency, 
governance, grantees and output, as for any other scientific or tobacco control effort. The Foundation will ultimately be evaluated on its impact on smokers and on poor tobacco farmers, and on its ability and willingness to support its collaborators and grantees if they are harassed. The responsibility of the scientific community is to defend the principle of open dialogue between peers, to hold the Foundation accountable and to take a stronger stand against harassment.

Declaration of interests

No competing interests.

Acknowledgements

No external funding. JFE's salary is paid by the University of Geneva. We thank the people who took part in interviews and shared information.

\section{References}

1. a, b, c, dWatts C., Freeman B. "Where There's Smoke, There's Fire": A Content Analysis of Print and Web-Based News Media Reporting of the Philip Morris-Funded Foundation for a Smoke-Free World, JMIR Public Health Surveill 2019: 5: e14067.

2. a, b, c Daube M., Moodie R., McKee M. Towards a smoke-free world? Philip Morris International's new Foundation is not credible, Lancet 2017: 390: 1722-1724.

3. ${ }^{a, b}$ Koh H. K., Geller A. C. The Philip Morris International-Funded Foundation for a Smoke-Free World, JAMA 2018: 320: 131-132.

4. ^Etter J. F. The Foundation for a Smoke-Free World after 2 years. E-cigarette Summit, London; 2019.

5. ${ }^{a, b}$ Delaware. Certificate of incorporation of the foundation for a smoke-free world, Inc.: State of Delaware; 2017.

6. ^NASEM. Public health consequences of e-cigarettes, National Academies of Sciences, Engineering and Medicine 2018: Washington, DC: The National Academies Press. doi: https://doi.org/10.17226/24952.

7. ^Levy D. T., Borland R., Lindblom E. N., Goniewicz M. L., Meza R., Holford T. R. et al. Potential deaths averted in USA by replacing cigarettes with e-cigarettes, Tob Control 2018: 27: 18-25.

8. ^PMI. Delivering a smoke-free future: Philip Morris international; 2019.

9. ${ }^{\mathrm{a}, \mathrm{b}}$ Diethelm P. A., Rielle J. C., McKee M. The whole truth and nothing but the truth? The research that Philip Morris did not want you to see, Lancet 2005: 366: 86-92.

10. a, barnoya J., Glantz S. A. The tobacco industry's worldwide ETS consultants project: European and Asian components, Eur J Public Health 2006: 16: 69-77.

11. ${ }^{a, b}$ van der Eijk Y., Bero L. A., Malone R. E. Philip Morris International-funded 'Foundation for a Smoke-Free World': 
analysing its claims of independence, Tob Control 2019: 28: 712-718.

12. ^Cohen J. E., Zeller M., Eissenberg T., Parascandola M., O'Keefe R., Planinac L. et al. Criteria for evaluating tobacco control research funding programs and their application to models that include financial support from the tobacco industry, Tob Control 2009: 18: 228-234.

13. ^ FSFW. Eight Criteria from Cohen, et al.ifor Accepting Tobacco Industry Funding, Compared to the Governance of the Foundation for a Smoke-Free World: Foundation for a Smoke-Free World; 2017.

14. ^Cohen J. E., Eissemberg T. Criteria not met for tobacco industry-supported foundation: Johns Hopkins Bloomberg School of Public Health; 2017.

15. ^FSFW. Return of private foundation. Form 990-PF; 2018.

16. ${ }^{a, b}$ Legg T., Peeters S., Chamberlain P., Gilmore A. B. The Philip Morris-funded Foundation for a Smoke-Free World: tax return sheds light on funding activities, Lancet 2019: 393: 2487-2488.

17. ^Yach D. Foundation for a Smoke-Free World: independent and making progress, Lancet 2019: $394: 1008$.

18. ^NIH. Research Project Success Rates by NIH Institute for 2018 U.S. National Institutes of Health; 2019.

19. ^ CRUK. Funding commitments for 2017/18 by our committees: Cancer Research UK; 2019.

20. ^SNF. Statistics 2018 - f ull version. Swiss National Science Foundation; 2019.

21. a, bCOREISS. Centre of Research Excellence: Indigenous Sovereignty \& Smoking: COREISS; 2019.

22. ^Espiner G. Māori smoking researcher Marewa Glover shunned over Philip Morris funding, Stuff 2019.

23. ^McKee M., Chapman S., Daube M., Glantz S. The debate on electronic cigarettes, Lancet 2014: $384: 2107$.

24. 'Shibuya K., Ciecierski C., Guindon E., Bettcher D. W., Evans D. B., Murray C. J. WHO Framework Convention on Tobacco Control: development of an evidence based global public health treaty, BMJ 2003: 327: $154-157$. 